\title{
A Autodeterminação dos POVOS no ESTAdo PlurinaCional: Da INTEGRAÇÃO LATINO-AMERICANA À OBJEÇÃO AOS EFEITOS PERVERSOS DA GLOBALIZAÇÃO
}

\author{
The SELF-Determination OF PEOPLES IN THE PluRinational State: From Latin \\ AMERICAN INTEGRATION TO AN OBJECTION TO THE PERVERSE EFFECTS OF GLOBALIZATION
}

\author{
Luiz Marcio Siqueira Junior ${ }^{1}$ \\ Michelle Abras ${ }^{2}$
}

\section{Resumo}

Recentemente surgiu na América Latina o Estado Plurinacional, inovando o constitucionalismo do mundo contemporâneo pela sua ousadia em promover a transição do sistema democrático de essência puramente representativa para o participativo e dialógico. Esse projeto constitucional rompe com as bases de uniformização de valores e a intolerância religiosa típicos do Estado nacional e inaugura uma nova ordem política que repercute na esfera internacional. O fundamento para criação de um modelo Estatal que prima pela reestruturação institucional é a radical exclusão de grupos sociais (étnicos e culturais) que se estende até a atualidade, e que remonta ao período de colonização pelos países ibéricos ao longo da idade moderna. A plurinacionalidade influencia diretamente na construção de uma nova conjuntura social, econômica e política, além de ser um fator relevante na consolidação do festejado ideal de integração dos povos latino-americanos. O reconhecimento e a preservação da diversidade apresentam certa afinidade com o princípio da autodeterminação dos povos e é, sem dúvida alguma, um instrumento poderoso para abrandar os efeitos negativos decorrentes da globalização.

Palavras-chave: Estado Plurinacional; autodeterminação dos povos; integração da América Latina; globalização; soberania.

\section{INTRODUÇÃO}

Tradicionalmente a América Latina foi palco de escândalos históricos que marcaram sensivelmente os povos que a habitam. É corriqueira a circulação de notícias envolvendo os latino-americanos, crucificados pela ganância européia. Traços de tal premissa encontram-se presentes na vexatória invasão de conquistadores espanhóis e portugueses que, além de terem

\footnotetext{
1 Mestre em Direito Público pelo Programa de Pós-graduação em Direito da Pontifícia Universidade Católica de Minas Gerais (2011). Graduado em Direito pela Pontifícia Universidade Católica de Minas Gerais (2009). Pesquisador membro do Núcleo Jurídico de Políticas Públicas (NUJUP). Professor convidado para lecionar Direito Tributário junto ao Projeto OAB da Pastoral da Pontifícia Universidade Católica de Minas Gerais. Professor voluntário na cadeira de Teoria Geral do Estado I da Faculdade de Direito da Universidade Federal de Minas Gerais (UFMG). Professor da Pontifícia Universidade Católica de Minas Gerais (PUCMinas), tendo lecionado Direito Constitucional II, Direito Empresarial II e Direito Romano e História do Direito. Tem experiência no Direito Público. Advogado.

2 Graduação em direito pela Universidade Federal de Minas Gerais (1999). É especialista em Direito Público pela Anamages (Newton de Paiva). É mestranda em Direito Público, pela PUC/MG, com bolsa da CAPES (modalidade II). Atualmente é professora de Direito Internacional e Processo Constitucional da Faculdade Minas Gerais. Tem experiência na área de Direito Público, Direito do Trabalho e Direito de Família.
}

Revista da Faculdade Mineira de Direito, v.13, n. 26, jul./dez. 2010 - ISSN 1808-9429. 
extinguido parte dos recursos naturais e minerais típicos do continente americano, também sepultaram milhões de indivíduos pertencentes aos povos originários ${ }^{3}$.

O desrespeito e a crueldade foram demasiadamente extensos a ponto de causar um constrangimento irrefutável aos diversos agrupamentos sociais, especialmente aos indígenas. Muitas civilizações tiveram suas culturas arrancadas à base da força das armas para implantação da doutrina religiosa pregada pela Igreja, e os índios foram abruptamente convertidos ao cristianismo e compelidos a engolir a cultura e os costumes de seus colonizadores. $^{4}$

Assistiram, ainda, sem meios de repelir o ataque devastador dos expugnadores europeus, à destruição de um império erguido e preservado pelos seus antepassados. A tragédia se alongou pelo tempo e, à medida que se estendia, cada vez mais vítimas padeciam da ação arbitrária e malévola perpetrada pelos invasores. Ao passo que a maldade operada aos povos originários se consumava, a opulência nos seus territórios se encolhia numa rapidez assustadora, até restar somente ruínas e lendas.

Esse pesadelo do qual os índios queriam se livrar os consumiu gradativamente, e acabou ocasionando a derrocada por completo das civilizações indígenas na América Latina. A extensão territorial ocupada pelo domínio das tribos chegava a ligar uma extremidade à outra do continente, e no final da incursão avassaladora dos países ibéricos sobrou apenas uma pequena porção de terra, onde se resumiu toda a história desses povos.

Contrapondo-se a essa fase de turbulência, aparece o Estado Plurinacional na tentativa de desencadear uma virada constitucional para romper com a lógica do terror vivenciada pelos

\footnotetext{
3 Essa expressão refere-se a um conjunto de indivíduos que originariamente habitam certo território, sendo que a fixação nesse espaço pode preceder a outros povos ou até mesmo ser prolongada e estável de modo a se reconhecer como nativos.

$4 \mathrm{Na}$ obra clássica, Os índios e o direito de guerra, publicada por Francisco de Vitória, o autor destaca os fundamentos pelos quais os espanhóis, principalmente, utilizavam para legitimar sua dominação sobre os índios, dentre os quais: “(...) o imperador é senhor de todo o orbe e, por conseguinte, também dos índios. (p. $60)$ ", “(...) o sumo pontífice é monarca de todo o mundo, temporal inclusive, e, consequentemente, pôde nomear os reis da Espanha como reis e senhores daqueles bárbaros e daquelas regiões; e, de fato, assim o fez. (p. 67)”, “(...) as terras desertas se tornam propriedade daqueles que as ocupam por direito das gentes e por direito natural. (...) Ora, como os espanhóis foram os primeiros que descobriram e ocuparam essas regiões, segue-se que as possuem por direito, do mesmo modo que se tivessem encontrado um deserto, até então desabitado. (p. 75)”, “(...) os índios são obrigados a aceitar a fé de Cristo, de acordo com as seguintes palavras: ‘Aquele que crer e for batizado, se salvará; aquele que não crer será condenado’. (p. 76)”, “(...) mesmo que não seja possível lhes mover guerra em razão de sua infidelidade ou porque não aceitam a fé cristã, podem, no entanto, ser atacados com armas por outros pecados mortais, uma vez que [os índios] os cometem em grande número e gravíssimos, como contam. (p. 86)”, “(...) quando os espanhóis chegaram ao território dos índios, informaram a estes que a eram enviados pelo rei da Espanha para seu bem e os exortaram para que o aceitassem como seu senhor e rei. (p. 89-90)” e “(...) o Senhor em seus desígnios condenou todos esses índios à perdição por suas abominações e os entregou nas mãos dos espanhóis, como em outros tempos entregou os cananeus nas mãos dos judeus. (p. 90)". Essas premissas incorporavam os argumentos da ingerência espanhola
} 
índios e demais grupos sociais durante a idade moderna. Certifica-se uma inversão do quadro histórico em que existiram terríveis barbáries e retrocessos para um momento de reconquista de direitos vilipendiados.

Do ostracismo ao reconhecimento da diversidade cultural e étnica, muitos fatos surgiram, embora ainda estejam pendentes muitos acontecimentos. O multiculturalismo certamente tem uma importância acentuada nesse período de transição, uma vez que serve de elo entre o passado de opressão, e o presente de reconstrução. Um grande passo foi dado em direção à concretização do objetivo da autodeterminação dos povos, e isso é inquestionável.

A retomada da gestão Estatal sob o espectro da pluralidade e com uma tendência forçosamente democrática concebe o enaltecimento da figura dos grupos oprimidos e explorados. Apagar de suas memórias a injustiça incessante a que foram submetidos será uma tarefa difícil em decorrência do trauma sentido na própria pele. Mas é possível reiniciar uma nova era em que a transformação social, econômica e política seja o motivo de mudança da América Latina.

O Estado Plurinacional, analisado sob essa ótica, enfatiza a encampação da soberania pelos grupos sociais desdenhados no passado. Sua vertente redescobre uma América Latina inclusive indígena, democrática, igualitária, social e culturalmente diversificada. Esses fatores recrudescem a esperança de união entre os povos latino-americanos para confrontar os fenômenos contemporâneos, tal como a globalização.

Essa constatação será realizada inicialmente pelo exame dos aspectos peculiares dos modelos de Estado Plurinacional implantados na América Latina, pela comprovação da aproximação entre o princípio da autodeterminação dos povos e esse paradigma Estatal, pela importância da proteção da diversidade cultural e étnica para a efetivação da integração entre os povos latino-americanos e pela proposta de reconfiguração Estatal baseada na concepção de plurinacionalidade, como condição para amenizar os efeitos perversos da globalização e como garantia para o exercício da soberania. É o que se passa a fazer.

\section{ASPECTOS PECULIARES DO ESTADO PLURINACIONAL NA AMÉRICA LATINA}

Recentemente, constata-se que os países latino-americanos têm apresentado um progresso marcante no setor social, e com uma participação efetiva de distintos povos, situação até então desconhecida na região. A partir da mobilização empreendida por

no decurso do período de colonização na América. Francisco de Vitória se notabilizou por questionar e refutar essas justificativas macabras.

Revista da Faculdade Mineira de Direito, v.13, n. 26, jul./dez. 2010 - ISSN 1808-9429. 
movimentos sociais houve conquistas importantes que retratam a cisão com um passado sombrio e retrógrado para diversos grupos sociais.

A abertura para um canal de comunicação mais estreito entre o Poder Público e a população se consolida cada vez mais em função do reconhecimento de direitos historicamente recusados aos povos originários da América Latina. Prioriza-se um modelo de institucionalização arvorado na democracia participativa, embora ainda perdurem resquícios do modelo democrático representativo, ou seja, nessa nova sistemática há representação de diversos grupos sociais na tomada de decisões políticas, sendo que os referidos segmentos participam amplamente das discussões sem qualquer tipo de limitação. ${ }^{5}$

Dentre as múltiplas facetas de democracia emergentes hodiernamente, destaca-se aquela baseada no paradigma do Estado Plurinacional, cujo objetivo se propõe a implantar uma nova realidade democrática em países explorados pelo domínio europeu ao longo de alguns séculos. Nesse sentido, busca-se iniciar uma transição pacífica através de revoluções conduzidas pela própria sociedade, no intuito de promover a reconquista da liberdade e da dignidade, precisamente nos Estados onde a maior parte da população é indígena.

As revoluções ocorridas na Bolívia e no Equador retratam um modelo de Estado oriundo da concepção de plurinacionalidade, em que os governos não são compostos apenas por representantes das camadas sociais dominantes, mas são, sobretudo, integrados por diversas categorias, inclusive a indígena, sob o formato de um processo eminentemente participativo e dialógico. ${ }^{6}$

O Estado Plurinacional não depende da uniformização de valores que sustentam a sociedade moderna, em que se acopla numa mesma base, o direito de família, o regime de propriedade e o sistema econômico. Pelo contrário, prioriza-se a construção de um

5 Agustín Grijalva salienta que as características do constitucionalismo no Estado Plurinacional deve ser dialógico, concretizante e garantista, verbis: "Este constitucionalismo [en el Estado Plurinacional] no puede sino ser dialógico, concretizante y garantista. Dialógico, porque requiere de comunicación y deliberación permanente para acercarse al entendimiento del otro, del diferente. El nivel constitucional cuando atañe a derechos de las nacionalidades y pueblos indígenas debe operar en términos interculturales.” (p. 52), “(...) Concretizante, porque debe buscar soluciones específicas y al tiempo consistentes para situaciones individuales y complejas; y a su vez tales soluciones deben derivar en generalizables para situaciones comparables." e "(...) Garantista, porque estas soluciones que surgen de la deliberación en torno a problemas y soluciones concretas deben tener por marco la comprensión y vigencia intercultural de los valores constitucionales institucionalizados en los derechos humanos." (p. 53)

6 José Luiz Quadros de Magalhães aponta que nas: “(...) revoluções da Bolívia e do Equador, seus poderes constituintes democráticos, fundam um novo Estado, capaz de superar a brutalidade dos estados nacionais nas Américas: o Estado Plurinacional, democrático e popular. Nunca na América, tivemos tantos governos democráticos populares como neste surpreendente século XXI. O importante é que estes governos não são apenas democráticos representativos, mas, fortemente participativos, dialógicos." O autor demonstra que esses Estados sul-americanos são exemplos que visualizam claramente as características elementares do Estado Plurinacional. MAGALHÃES, José Luiz Quadros de. O Estado Plurinacional na América Latina. Disponível em: 〈http://jusvi.com/artigos/38959>. Acesso em: 27/10/10. 
mecanismo que permite aos múltiplos grupos sociais o reconhecimento entre si. Consequentemente deve-se incentivar os agrupamentos étnicos ou culturais a criticar e protestar contra o propósito da uniformização de valores fomentado por essa espécie de sociedade de estirpe européia, como forma de impedir o isolamento cultural, social, político e econômico. ${ }^{7}$

A reformulação das bases constitucionais impõe ainda a desvinculação do Estado da religião, tornando-o laico, para evitar qualquer tipo de dissidência dos grupos sociais ou causar restrições por questões de crença ou convicção religiosa. A ausência de preferência por religião, assim como fez o Brasil ainda em Constituições pretéritas, é importante para viabilizar a proposta de inclusão, o que certamente seria dificultado se esse projeto constitucional tomasse partido, a exemplo dos Estados islâmicos.

Busca-se instituir um novo viés constitucional fundado na participação popular para romper com o modelo de Estado embasado na obsoleta sistemática da democracia representativa. Dessa forma, é possível edificar a democracia participativa e dialógica e, concomitantemente, assegurar a constituição da família e da economia sem afetar os valores tradicionais que orientam os vários grupos sociais.

A descentralização da legislação eleitoral também corresponde a um grande avanço, porque garante aos povos indígenas participação plena no governo, já que parte dos cargos de mandato eletivo são reservados a esse grupo. A eleição é realizada inclusive entre as comunidades indígenas para escolha de seus representantes, não participando desse pleito eleitoral outros grupos sociais e culturais. ${ }^{8}$

Realça-se ainda a existência de um Tribunal Constitucional com feição plurinacional, composto de membros eleitos pelo sistema ordinário e pelo sistema indígena, sendo resguardado a equivalência da justiça dos índios com a comum, e vedada qualquer tipo de

7 A uniformização de valores e comportamentos, causa da exclusão social e cultural, são atributos do antiquado Estado nacional e a ruptura com esse modelo justifica-se através do processo democrático dialógico e amplamente popular. MAGALHÃES, José Luiz Quadros de. O Estado Plurinacional na América Latina. Disponível em: <http://jusvi.com/artigos/38959>. Acesso em: 27/10/10.

8 "Artículo 211: I. La organización y funcionamiento de las organizaciones de las naciones y pueblos indígena originario campesinos, las agrupaciones ciudadanas y los partidos políticos deberán ser democráticos. II. La elección interna de las dirigentes y los dirigentes y de las candidatas y los candidatos de las agrupaciones ciudadanas y de los partidos políticos será regulada y fiscalizada por el Consejo Electoral Plurinacional, que garantizará la igual participación de hombres y mujeres. III. Las organizaciones de las naciones y pueblos indígena originario campesinos podrán elegir a sus candidatas o candidatos de acuerdo con sus normas propias de democracia comunitaria.

Artículo 212: Las naciones y pueblos indígena originario campesinos podrán elegir a sus representantes políticos en las instancias que corresponda, de acuerdo con sus formas propias de elección."

Revista da Faculdade Mineira de Direito, v.13, n. 26, jul./dez. 2010 - ISSN 1808-9429. 
revisão das decisões proferidas pelos tribunais preenchidos exclusivamente por membros dos povos originários. ${ }^{9}$

O resultado da criação do Estado Plurinacional corresponde à transformação social e à eficácia de direitos individuais e coletivos fundamentais, além do surgimento de uma nova ordem política, econômica e social na esfera internacional. O mais importante é que a América Latina se apresenta com outra roupagem, agora com características genuinamente constitucionais, especialmente por reconhecer os direitos dos indígenas, priorizar a participação popular, a igualdade econômica entre os povos e a diversidade social e cultural. ${ }^{10}$

A heterogeneidade nos Estados onde co-existem muitos grupos étnicos reflete também aspectos relativos às variadas identidades (étnicas ou culturais), principalmente no combate às formas de exclusão. A superação das bases uniformizadoras e intolerantes do Estado nacional tem como finalidade resgatar a história e a cultura dos povos originários, em contraposição à imposição da cultura européia, tanto em relação ao direito de família, quanto ao direito de propriedade.

O novo constitucionalismo, vanguardista e inovador, apóia-se em relações interculturais igualitárias que redefinam e reinterpretam os direitos constitucionais e, sobretudo, que remodela a institucionalização procedente do Estado nacional. A igualdade na

9 Assim dispõe a Constituição boliviana: “Artículo 180: I. La función judicial es única. La jurisdicción ordinaria se ejerce por el Tribunal Supremo de Justicia, los tribunales departamentales de justicia, los tribunales de sentencia y los jueces; la jurisdicción agroambiental por el Tribunal y jueces agroambientales; la jurisdicción indígena originaria campesina se ejerce por sus propias autoridades; existirán jurisdicciones especializadas reguladas por la ley. II. La jurisdicción ordinaria y la jurisdicción indígena originario campesina gozarán de igual jerarquía. III. La justicia constitucional se ejerce por el Tribunal Constitucional Plurinacional. IV. El Control Administrativo Disciplinario de Justicia es parte del Órgano Judicial." Garante-se a existência da Justiça Indígena paralelamente à Justiça Comum e, no caso do Tribunal Constitucional, assegura-se a representação paritária, senão vejamos: "Artículo 198: I. El Tribunal Constitucional Plurinacional estará integrado por Magistradas y Magistrados elegidos con criterios de plurinacionalidad, con representación paritaria entre el sistema ordinario y el sistema indígena originario campesino. [...]"

$10 \mathrm{O}$ preâmbulo da Constituição boliviana marca o surgimento de uma nova era do constitucionalismo, e isso se expressa pelo sentimento do povo quando, reunido em Assembléia Nacional Constituinte, profere as seguintes palavras: "El pueblo boliviano, de composición plural, desde la profundidad de la historia, inspirado en las luchas del pasado, en la sublevación indígena anticolonial, en la independencia, en las luchas populares de liberación, en las marchas indígenas, sociales y sindicales, en las guerras del agua y de octubre, en las luchas por la tierra y territorio, y con la memoria de nuestros mártires, construimos un nuevo Estado. Un Estado basado en el respeto e igualdad entre todos, con principios de soberanía, dignidad, complementariedad, solidaridad, armonía y equidad en la distribución y redistribución del producto social, donde predomine la búsqueda del vivir bien; con respeto a la pluralidad económica, social, jurídica, política y cultural de los habitantes de esta tierra; en convivencia colectiva con acceso al agua, trabajo, educación, salud y vivienda para todos. Dejamos en el pasado el Estado colonial, republicano y neoliberal. Asumimos el reto histórico de construir colectivamente el Estado Unitario Social de Derecho Plurinacional Comunitario, que integra y articula los propósitos de avanzar hacia una Bolivia democrática, productiva, portadora e inspiradora de la paz, comprometida con el desarrollo integral y con la libre determinación de los pueblos."

Revista da Faculdade Mineira de Direito, v.13, n. 26, jul./dez. 2010 - ISSN 1808-9429. 
relação entre os povos e culturas não implica, contudo, em eliminar as diferenças ou as diversidades, mas somente impedir privilégios de uns em relação aos outros. ${ }^{11}$

Da mesma maneira, é preciso impedir a competição e a dominação entre os grupos, de modo que os menos expressivos sejam manipulados pelos maiores e mais organizados. Por isso é importante enfatizar um governo multi-cultural que favoreça um modelo de instituições que permitam superar as desigualdades entre os grupos sociais, assim como as desigualdades no interior de cada um destes.

O Estado Plurinacional prioriza o compartilhamento do poder político para sacralizar um regime democrático nos Estados vitimados pelo autoritarismo. Isso é uma resposta ao extenso processo histórico de dominação iniciado pelos europeus e herdado pelas elites sociais opressoras que acarretou na supressão de direitos constitucionais de diversos grupos étnicos e culturais. ${ }^{12}$

A plurinacionalidade tem plausibilidade na medida em que cria condições do povo, especialmente os grupos sociais minoritários, tomar suas próprias decisões políticas e jurídicas no território que ocupa. ${ }^{13}$ Nesse sentido vislumbra-se uma correlação entre a ideia de autodeterminação do povo e o Estado Plurinacional. Eis o que será analisado a seguir.

11 Segundo José Luiz Quadros de Magalhães, “Inicialmente não democrático, o constitucionalismo irá uniformizar (junto com o direito civil) as bases valorativas desta sociedade nacional, criando um único direito de família e um único regime de propriedade que sustentaria o sistema econômico.” MAGALHÃES, José Luiz de Quadros. Plurinacionalidade e cosmopolitismo: a diversidade cultural das cidades e diversidade comportamental nas metrópoles. Disponível em: <http://jus.uol.com.br/revista/texto/14564/plurinacionalidadee-cosmopolitismo-a-diversidade-cultural-das-cidades-e-diversidade-comportamental-nas-metropoles > Acesso em: 27/10/10.

$12 \mathrm{O}$ referido autor sustenta ainda que: "A idéia de Estado Plurinacional supera as bases uniformizadoras e intolerantes do Estado nacional, onde todos os grupos sociais devem se conformar aos valores determinados na constituição nacional em termos de direito de família, direito de propriedade e sistema econômico entre outros aspectos importantes da vida social." MAGALHÃES, José Luiz de Quadros. Plurinacionalidade e cosmopolitismo: a diversidade cultural das cidades e diversidade comportamental nas metrópoles. Disponível em: <http://jus.uol.com.br/revista/texto/14564/plurinacionalidade-e-cosmopolitismo-a-diversidade-culturaldas-cidades-e-diversidade-comportamental-nas-metropoles > . Acesso em: 27/10/10.

13 Peter A. Kraus evoca que o sucesso do Estado Plurinacional sujeita-se ao risco do dever de lealdade dos cidadãos, pois se houver tensões internas entre os grupos pode ocorrer a quebra dos vínculos sociais em função de conflitos de interesses. Nesse sentido, o autor aponta que: "La aplicabilidad de un procedimiento democrático tan elemental como lo es la regla de la mayoría presupone la existencia de una comunidad política reconocida por los ciudadanos como el marco general y legítimo que les permite articular sus pertinencias individuales y colectivas. Sin este tipo de reconocimiento, las tensiones inherentes a la movilización de intereses de grupos enfrentados siempre entrañanan el riesgo de romper aquellos vínculos sociales que precisamente justifican el mantenimiento de un orden democrático común, y más aun si los conflictos de intereses, sean ya de origen funcional o cultural, tienen una marcada dimensión territorial. Cuando se produce tal circunstancia, el repertorio estratégico de la acción política colectiva ya no se limita a intensificar la «voz» o a retirar la «lealtad». Entra en juego la «salida» como tercera opción a considerar, y ya no en un sentido metafórico, sino absolutamente literal: la «salida» se convierte en secesión.” (p. 60-61)

Revista da Faculdade Mineira de Direito, v.13, n. 26, jul./dez. 2010 - ISSN 1808-9429. 


\section{A SINTONIA ENTRE O PRINCÍPIO DA AUTODETERMINAÇÃO DOS POVOS E O ESTADO PLURINACIONAL}

A autodeterminação ${ }^{14}$ de um povo exterioriza-se pela sua autonomia na tomada de decisões políticas e jurídicas dentro do território por este dominado. Outrossim, trata-se do direito de se auto-governar sem a imposição de limitações externas, sendo assegurado o estabelecimento do próprio status político e das diretrizes do desenvolvimento econômico, social e cultural.

Isso decorre da sua soberania perante outros povos, e essa independência política opõe-se à colonização ou qualquer outro tipo de dominação exterior. Assim, a aspiração de um grupo com identidade distinta e capacidade de auto-governo evidencia seu controle sob uma determinada área territorial. É nessa perspectiva que os povos se orientam sem a necessidade de seguir regras e fórmulas tabuladas por agentes estranhos. ${ }^{15}$

A ideia de autodeterminação dos povos encontra guarida no paradigma do Estado Plurinacional em função da reorganização institucional promovida para construir uma nova realidade constitucional em que o povo, enquanto titular legítimo do poder soberano, assume a direção da ordem política, econômica e social e é capaz de romper com a intolerância unificadora e violenta de séculos de existência do Estado nacional.

A reviravolta democrática iniciada na América Latina não apenas resgatou a soberania popular, como também desconstituiu o arquétipo uniformizador do Estado moderno sustentado pelo sistema capitalista que retirou dos povos originários sua história e cultura. Esses povos perderam a autonomia devido à adesão compulsória de uma política econômica que transformou territórios nacionais em uma economia globalizada para favorecer a livre circulação de capital financeiro, que se funda no direito de família e de propriedade europeu.

A construção de um Estado inspirado no ideal democrático, especialmente baseado na participação e no diálogo, é essencial para combater o aviltamento dos grupos sociais latinoamericanos. Somente com a representação efetiva nos órgãos públicos (como o Legislativo e Judiciário) é que será possível salvaguardar seus interesses por justiça social e econômica. O

\footnotetext{
14 Giuliana Redin aponta que: “O direito à autodeterminação dos povos pressupõe muito mais do que apenas o direito do povo de ser governado por pessoas que ele mesmo escolheu, mas sim a necessidade de evolução espiritual do povo que forma a base da nação, que não apenas tenha definida uma identidade cultural, mas que possa se afirmar enquanto sociedade com plena capacidade de escolha. Autodeterminação é a capacidade do povo garantir por meio do autogoverno sua liberdade substancial, garantida pela efetiva cidadania.” (p. 26)

15 Ian Brownlie destaca que o princípio da autodeterminação dos povos tem repercussão interna e externa, pois este “(...) inspira e completa (...) a soberania do Estado, a igualdade dos Estados e a igualdade dos povos dentro de um Estado.” (p. 619)
} 
Estado Plurinacional apresenta essa característica que é a mais propícia em evitar o banimento da autodeterminação dos povos. ${ }^{16}$

A democracia participativa e dialógica é o caminho mais sensato e equilibrado na integração de diversos grupos sociais (étnicos e culturais). $\mathrm{O}$ povo contribuindo significativamente para o processo decisório político e jurídico pode fazer desencadear algo inédito contra essa época marcada pelo egoísmo e competição entre empresas transnacionais e Estados. A contenção da desigualdade social e econômica que afeta os países latinoamericanos pode ser alcançada partindo-se de uma reformulação interna que, dentre outros mecanismos, consiste no reconhecimento da diversidade cultural e étnica e no exercício do poder soberano por esses grupos.

Erguer as bases de um Estado fundado na concepção de plurinacionalidade que priorize a participação plena de toda a sociedade civil na criação de instrumentos capazes de proporcionarem seu auto-governo, a preservação de sua história e cultura e, sobretudo, a condução de seu próprio desenvolvimento econômico, social e cultural representa o fim da imagem oprimida e sucateada da América Latina. ${ }^{17}$

Esse processo pode começar pela reconfiguração da estrutura interna dos Estados latino-americanos como uma forma de sintonizá-los às tendências do mundo moderno sem que haja a perda de suas soberanias e seja afetada a autodeterminação dos povos. O Estado Plurinacional é um caminho possível na medida em que reconhece e favorece a diversidade étnica e cultural, além de possibilitar a reorganização institucional e fomentar a presença dos variados grupos na administração Estatal.

A entronização do Estado Plurinacional contrapõe-se à negação ao diferente, à inflexibilidade religiosa e cultural, além de descontruir o arcabouço do Estado nacional

$16 \mathrm{O}$ combate ao isolamento dos grupos sociais depende de políticas públicas inclusivas que priorizem suas autonomias. Segundo Ileana Almeida, "La exigencia de autonomía, como un modo de ejercer determinados grados de soberanía, encuentra, entonces, explicácion lógica entre los indios que perciben claramente su desconexión com el Estado. Resulta, asimismo, natural su propuesta de establecer um Estado plurinacional, es decir uma estructura que contemple espacios para las diversas propuestas políticas de las nacionalidades indígenas del Ecuador.” (p. 62) A autora ainda afirma que para prevalecer a autonomia é necessário que: “(...) los pueblos indígenas integren las instancias gubernarmentales mediante su representácion em los grupos parlamentarios, su actuácion em los estamentos de las gestiones ministeriales y su participación em la administración provincial y cantonal; en fin, su presencia como pueblos peculiares em el seno de las instituciones que deciden e influyen en las determinaciones políticas y econômicas.” (p. 62).

17 Luís Tapia defendendo a concepção do Estado Plurinacional sustenta que: “(...) un Estado plurinacional que enfrente el problema de la igualdad entre pueblos y culturas, a la vez que el problema de la desigualdad en el seno de cada una de ellos, podría funcionar para favorecer el poder de algunos núcleos particulares. Por eso, tal vez es preferible pensar en una forma de gobierno democrático multicultural que ponga énfasis en el diseño de instituciones que permitan ir superando las desigualdades entre naciones y pueblos así como las desigualdades al interior de cada uno de estos; es decir, afirmar la primacía de lo democrático por sobre lo nacional, ya que la historia nos muestra que no sólo las construcciones nacionales, sino también las plurinacionales, han producido sus formas de monopolio político y una estructura de clases." (p. 62)

Revista da Faculdade Mineira de Direito, v.13, n. 26, jul./dez. 2010 - ISSN 1808-9429. 
desenvolvido pela parcela minoritária da população como forma de satisfação de seus anseios. Em decorrência disso que inúmeros latino-americanos, assim como os indígenas, foram relegados à miséria e extirpados da noção de nacionalidade.

$\mathrm{Na}$ essência do Estado nacional, prevalecia a identidade nacional e a recusa da diversidade, buscando-se o enquadramento de um único grupo de indivíduos como iguais. Os indígenas, os negros e os demais grupos sociais eram tidos como diferentes e, portanto, não se esperava que comportassem como iguais, o que os levaram aos milhões ao isolamento social, econômico e cultural.

A autodeterminação foi mitigada durante muito tempo e se restabelece sob o amparo da plurinacionalidade. Inúmeros relatos históricos atestam o massacre aos povos originários, que suprimiu suas autonomias, subverteu seus valores e crenças e submeteu-os à exploração e ao extermínio. Nesse sentido é que se vislumbra uma grande sintonia entre a autodeterminação dos povos e o Estado Plurinacional, já que este modelo Estatal promove o retorno dos grupos sociais abandonados como protagonistas da nova ordem constitucional latino-americana.

A plurinacionalidade tem importância acentuada na perspectiva da reformulação constitucional, precisamente na consolidação de um sistema democrático estruturado na participação popular e na proteção dos direitos fundamentais, sobretudo, dos povos originários. Sob esse viés, sustenta-se que a diversidade étnica e cultural também pode influenciar a integração dos Estados latino-americanos, muitos constituídos em sua maioria por grupos sociais afligidos historicamente. É o que se analisa adiante.

\section{A PROTEÇÃO DA DIVERSIDADE ÉTNICA E CULTURAL NO ÂMBITO INTERNO E A QUESTÃO DA INTEGRAÇÃO LATINO-AMERICANA}

A integração entre os povos na América Latina depende de uma série de fatores, a começar pela questão interna dos Estados. O primeiro passo certamente deve passar pela resolução de problemas estruturais básicos como: a educação, saúde, saneamento básico, meio ambiente, moradia, enfim. Além disso, é inerente que se efetive a proteção da história e da cultura dos povos originários e demais agrupamentos sociais que foram afastados do convívio social em função de suas diferenças.

Isso se deve ao fato de países latino-americanos se constituírem em grande parte por múltiplas etnias e culturas, tendo alguns destes os indígenas como a categoria prevalecente. Integrar povos não depende exclusivamente da harmonia de interesses sociais, econômicos e 
políticos entre diferentes Estados, mas também de uma identificação dos povos, inaugurada pelo reconhecimento dessa diversidade.

Negar a existência ou a condição do status político e jurídico de grupos sociais como: os indígenas, negros, cafuzos, cablocos e demais mestiços pode ser um óbice ao processo de integração entre os países do continente americano. Essa dificuldade precisa ser superada no âmbito interno através de políticas públicas inclusivas que, de uma forma plausível, está sendo trabalhada pelo projeto constitucional do Estado Plurinacional no Equador e na Bolívia.

A relevância disso para a integração da América Latina é evidente em razão de impedir que ocorram atritos entre povos de diferentes Estados. Se cada um destes eliminar as formas de discriminação e perseguição de grupos sociais menos expressivos ou com características diversificadas, menos empecilhos serão enfrentados na tentativa de lutar por interesses comuns envolvendo esses países.

Não resta dúvida que para se atingir o escopo almejado de unir os povos latinoamericanos é necessário proporcionar condições efetivas de proteção às culturas e etnias. A emancipação contra o império capitalista, que suprimiu desses povos a autonomia política e jurídica sobre seus territórios, está condicionada ao fortalecimento do movimento revolucionário pacífico instalado na Bolívia e no Equador, de modo que seus ideais se estendam por toda a América Latina.

Essa luta pertence aos numerosos grupos espalhados pelo continente americano e é fruto de reivindicações históricas. Recentemente é que esses povos se mobilizaram e se organizaram para empreender uma mudança no quadro político nos países onde são considerados nacionais. ${ }^{18}$ É essa pressão exercida em face das elites dominantes, em que se propugna por proteção de suas origens, que simboliza o marco introdutório da unificação latino-americana.

Indubitavelmente a assistência aos movimentos sociais, apesar de tudo, está ligada à existência de vontade política. É óbvio que a reação das comunidades periféricas atenta contra as pretensões governamentais e por isso se depara com resistências opostas. Não é nada conveniente que a maioria excluída e oprimida proteste com veemência a ponto de comprometer a estabilidade política consolidada pela minoria dominante.

18 Lúcio Flávio Rodrigues de Almeida critica a falência dos movimentos sociais e operários e os reflexos disso na implementação de políticas públicas sociais pelo Estado. A situação é tão caótica que já começa a ser insustentável as conquistas históricas daqueles movimentos. Porém, o seu ressurgimento relaciona-se com o resgate da cidadania, o que evidentemente vem acontecendo nos Estados adeptos do modelo plurinacional. Segundo o autor, "A maioria dos Estados teve reduzida sua capacidade de implementação de políticas sociais, inclusive no que se refere à permanência de conquistas dos movimentos operários e populares. Não chega a ser 
A manutenção do status da nata burguesa tem seu pilar fundamental no afastamento dos movimentos sociais do poder político. Para que isso se consume, as eleições são manipuladas pela força dos meios de comunicação em massa, que passam a ser controlados e financiados pelo grande capital, como forma de inviabilizar o ingresso de grupos reacionários nos cargos de tomada de decisão.

Essa manobra é realizada no intuito de instaurar uma hegemonia tirânica sobre as multidões culturais e étnicas, tornando perpétua essa lógica de subjugação que assola, principalmente, os povos originários. Pior do que isso são esses povos assistirem a entrega do Estado às instituições financeiras internacionais (Banco Mundial e Fundo Monetário Internacional), e passivamente observarem a retirada das riquezas nacionais como a água potável e outros recursos naturais do seu próprio domínio.

Concomitantemente a essa situação, observa-se que é imperioso obstruir a usurpação dos direitos das minorias, já que isso é um atentado aos valores democráticos e republicanos. Ressalta-se que a integração dos mercados nacionais no cotidiano, como efeito da globalização econômica, aliado ao surgimento das empresas transnacionais, tem acirrado a competição no comércio internacional, fazendo com que os países enxerguem o problema, que é competirem sozinhos nesse mundo dominado pela Lex Mercatoria e, cujo resultado, tem levado à formação dos blocos econômicos.

A América Latina deve explorar ao máximo sua diversidade cultural e desta extrair os elementos necessários para promover uma integração que a permita lutar contra essa tentativa de hegemonia dos países do Norte. A idéia da plurinacionalidade é fundamental na promoção dessa integração, na medida em que avoca a participação de uma parcela da sociedade latinoamericana que sempre esteve à margem das decisões políticas, o que reflete um desrespeito aos direitos fundamentais da pessoa humana.

A proteção da diversidade na América Latina tornou-se uma questão de sobrevivência e ainda se apresenta como o fator precípuo para se construir uma aliança legítima entre os Estados. Assim, a integração latino-americana pode se resolver pela preservação do multiculturalismo e pelo equacionamento das complexidades sociais, e não somente pelo estreitamento dos vínculos políticos e econômicos entre povos que partilham um passado histórico semelhante e que também são vizinhos territoriais. ${ }^{19}$

surpreendente que estes movimentos, ao voltarem à tona, apresentem um certo teor de estatismo articulado à luta pelo chamado "resgate da cidadania'." (p. 70)

19 Para concretizar a integração dos povos latino-americanos seria preciso, segundo Ramón Máiz, que as comunidades nacionais se considerem: “(...) 1) culturalmente plural, resultado de multiplicidad de prácticas creencias, significaciones, narrativas y usos lingüísticos; y 2) abierta al exterior, resultado de un flujo de 
Dirimir as complicações e distorções oriundas de tempos remotos requer muito mais do que simples manifestações de protesto das sociedades. Essa situação comporta uma cooperação entre os povos pelo fato de haver coincidência nas deformidades sociais que afetam substancialmente a proteção à diversidade cultural e étnica nos países latinoamericanos. Nesse sentido é viável dar ênfase a um processo de identidade política e cultural entre povos de diferentes Estados.

A elaboração de políticas públicas destinadas a promover a proteção aos povos originários demonstra ser urgente. E o melhor caminho para implementá-las passa pela compreensão e aplicação do modelo de Estado baseado na plurinacionalidade. Dessa forma, o Estado Plurinacional oferece indícios de que a alternativa mais acertada consiste no reconhecimento dos diversos grupos sociais e na preservação de suas histórias e culturas para se alcançar a decantada integração na América Latina.

O novo padrão constitucional introduzido nos Estados boliviano e equatoriano acena para a reconfiguração da estrutura Estatal. A democracia participativa e dialógica e a retomada do controle dos recursos naturais pelos povos latino-americanos são a tônica de um modelo desenvolvido para proporcionar a autodeterminação, além de ser um instrumento capaz de mitigar os efeitos nefandos da globalização. É o que se aborda a seguir.

\section{A RECONFIGURAÇÃO ESTATAL BASEADA NA IDEIA DE PLURINACIONALIDADE COMO SOLUÇÃO PARA AS MAZELAS CAUSADAS PELA GLOBALIZAÇÃO E COMO GARANTIA DO EXERCÍCIO DA SOBERANIA}

Eliminar a presença das consequências perversas ou do impacto indireto da globalização parece ser algo inatingível e até mesmo ilusório. ${ }^{20}$ Essa situação é provocada e

\footnotetext{
intercambios, incorporaciones, resignificaciones y mestizajes; 3) cambiante y procesal, resultado de las experiencias y luchas internas y externas, de los coyunturas criticas que condicionan su evolución histórica; y 4) conflictiva, esto es, objeto de narrativas en competición, de disputas por la hegemonia en la imposición de una versión determinada, de una articulación siempre contestable de interesses nacionales e interesses de grupos." Criando uma identidade entre os povos de diferentes Estados, talvez se possa aproximá-los e estimulá-los a uma interação maior, o que seria mais extenso do que as relações políticas, jurídicas econômicas. MÁIZ, Ramon. Nacionalismo y multiculturalismo. Disponível em: <http://red.pucp.edu.pe/ridei/buscador/files/081116.pdf>. Acesso em: 29/10/10.

20 Milton Santos faz uma crítica ao sistema globalizado afirmando que o progresso tecnológico e da medicina são, contraditoriamente, insuficientes para conter o desenvolvimento dos seus efeitos mórbidos. A competitividade e o egoísmo aliados à hipocrisia e à corrupção conduzem às sociedades modernas à pobreza e facilitam a reinstalação de um quadro crônico de mortes, fome e desespero que relembram os períodos de guerra. Nesse sentido, o autor deixa claro que: “(...) para a grande maior parte da humanidade a globalização está se impondo como uma fábrica de perversidades. $\mathrm{O}$ desemprego crescente torna-se crônico. A pobreza aumenta e as classes médias perdem em qualidade de vida. O salário médio tende a baixar. A fome e o desabrigo se generalizam em todos os continentes. Novas enfermidades como a SIDA se instalam e velhas doenças, supostamente extirpadas, fazem seu retorno triunfal. A mortalidade infantil permanece, a despeito dos progressos médicos e da informação. A educação de qualidade é cada vez mais inacessível. Alastram-se e
} 
chancelada pelos próprios agentes capitalistas, que se pautam no acúmulo desmedido de riqueza. ${ }^{21}$ Contudo, isso não significa que possam ser criados mecanismos eficientes para abrandar os resultados maléficos produzidos pelo capitalismo, a fim de resguardar a soberania dos Estados e, sobretudo, a autodeterminação dos povos.

A reengenharia constitucional a partir da instituição de um modelo de Estado baseado na ideia de plurinacionalidade pode ser uma possibilidade de amortização das complicações causadas pela globalização e também um meio eficiente de assegurar a diversidade entre os povos. $\mathrm{O}$ aprimoramento das instituições Estatais, a interpretação adequada dos princípios de direitos fundamentais, a democratização da estrutura dos partidos políticos (e dos órgãos públicos) e a adequação das instituições democráticas às normas e estruturas supranacionais podem ser instrumentos de proteção às diversidades culturais e étnicas, além de ser uma panacéia para combater o agravamento da desigualdade social e econômica que enseja uma assimetria entre os países do norte e do sul do mundo. ${ }^{22}$

A internacionalização do Estado Plurinacional desencadeia o nascimento de uma América Latina renovada e integrada. O Rompimento com a intolerância unificadora que perdurou por séculos consagra uma nova ordem política, social, econômica e até mesmo plural. Essa transição representa, mormente, a proteção ao multiculturalismo, o revigoramento das instituições democráticas e o término da era de opressão e domínio sobre os povos originários. Soma-se a isso o fato de surgir um fenômeno pioneiro que rechaça os desequilíbrios persistentes, profundos, eticamente inaceitáveis e politicamente insustentáveis provocados pelos efeitos negativos da globalização.

aprofundam-se males espirituais e morais, como os egoísmos, os cinismos, a corrupção. A perversidade sistêmica que está na raiz dessa evolução negativa da humanidade tem relação como a adesão desenfreada aos comportamentos competitivos que atualmente caracterizam as ações hegemônicas. Todas essas mazelas são direta ou indiretamente imputáveis ao presente processo de globalização.” (p. 19-20)

21 Conforme assevera Wallerstein o sistema é alimentado pelos próprios agentes dominantes, que montam um regime econômico para funcionar de acordo com suas conveniências. Então, o autor conclui que: "O dominante precisa sentir que se justifica moral e historicamente como grupo dominante e principal receptor do excedente econômico produzido dentro do sistema." (p. 65)

22 Mário Lúcio Quintão Soares aponta que, diante do contexto de incertezas e insegurança provocado pelo fenômeno da globalização, é preciso definir novos parâmetros da hermenêutica dos direitos fundamentais, assim como fez a Bolívia e o Equador ao renovarem suas bases constitucionais. Portanto, o autor mencionado reafirma que para isso ocorrer alguns objetivos elementares devem ser satisfeitos, tais como: "aplicar e concretizar mecanismos que aprimorem as instituições estatais, ajustando-os ao Estado democrático de direito; adotar a metódica adequada para interpretação e densificação dos princípios de direitos fundamentais; penetrar na reestruturação do sistema de partidos, na vida e funcionamento das forças políticas, buscando democratizálas; criar mecanismos que preservem as instituições democráticas, refletindo na imagem de Estado a ser recepcionada pelas instituições supranacionais, não esquecendo que o Estado contemporâneo está condicionado aos princípios básicos do Direito Comunitário, abrangendo normas e estruturas supranacionais e o controle dos interesses das multinacionais.” (p. 184) 
Apresentar uma solução equilibrada, totalmente exata e livre de valores préestabelecidos parece destoar daquilo que é aparentemente real, ainda mais se se considerar o panorama do mundo contemporâneo, que se consagrou pelo padrão unipolar e por estar submetido ao controle de uma ordem econômica mundial dirigida pelos países situados ao norte da linha do equador. Todavia, propor um mecanismo eficiente, simples e universal para impedir os avanços catastróficos da globalização e que, simultaneamente, alavanque a reconquista da autodeterminação dos povos latino-americanos e ainda inicie o processo de integração da América Latina, é algo plenamente possível.

A reforma do Estado tem como pretensão transformar as suas bases estruturais a partir de uma reordenação das instituições democráticas. Ignora-se a ordem anterior constituída sob uma tensão permanente entre os povos, em que os indígenas e demais agrupamentos sociais foram radicalmente lançados à pobreza e tratados como meros selvagens. O Estado Plurinacional reencontra as origens dos povos originários enaltecendo-os e reconhecendo-os como portadores de direitos fundamentais e legítimos detentores do poder soberano, assim como os demais civis.

Repensar o constitucionalismo faz parte da evolução das relações sociais e é essencial para aperfeiçoar a democracia, além de preservar a segurança jurídica e os direitos fundamentais diante das cobiças da elite autoritária ou sem limites. Esse fenômeno atípico de revisão constitucional, quando empreendido em Estados arrasados pela violação de direitos básicos, é salutar por remodelar o jogo de forças econômicas, sociais e políticas.

As consequências disso refletem tanto na esfera interna quanto na externa, primeiro porque o povo reassume a soberania de seu território e do seu poder soberano e, segundo, porque o Estado se revigora para fazer frente à globalização. A soberania na acepção interna está vulnerável em razão do povo (exclusive os múltiplos grupos sociais) não ter condições de tomar suas decisões políticas. Por outro lado, na perspectiva externa a soberania está ameaçada em função da ausência de autonomia perante a ordem internacional, pelo endividamento desses Estados e pela sujeição à política econômica internacional estabelecida pelas potências mundiais.

A política econômica mundial tem suporte na fragilidade do aparato Estatal e é disseminada: pela desvalorização da moeda, desindexação dos salários, perda do controle do Banco Central para regular a taxa de câmbio, privatizações de empresas públicas, privatização de terras públicas cultiváveis, corte de investimentos públicos, liberalização do mercado, reforma fiscal, aumento da importação de produtos básicos e tantas outras medidas que ataram os governos nacionais. Assim, somente com a reformulação do Estado que os povos 
originários podem obter a libertação contra o monopólio do poder político exercido pelas elites internas e contra as determinações advindas das instituições externas. ${ }^{23}$

A sofisticação do arcabouço dos Estados latino-americanos preconiza um progresso notável no enfrentamento e prevenção contra os desdobramentos da globalização. E o paradigma de Estado Plurinacional se desenvolve atrelado nessa compreensão, cujo marco consiste na mobilização popular fundada na democracia dialógica e participativa que, na atual conjuntura, é a justificativa mais avançada para rupturas constitucionais profundas. Talvez seja essa a forma mais adequada para se pensar a América Latina no contexto da ordem internacional. ${ }^{24}$

\section{CONCLUSÃO}

O Estado Plurinacional sintetiza um plano de restabelecimento constitucional através da modificação do sistema democrático representativo para o participativo e dialógico. $\mathrm{O}$ distanciamento do paradigma de Estado nacional marca o rompimento com a intolerância religiosa e a uniformização de valores. O contraponto ao sistema capitalista evidencia-se por esse repúdio ao direito de família, ao direito de propriedade e ao sistema econômico padronizado pela sociedade européia e implantado na América Latina.

Erradicar as formas de dominação que inviabilizam a existência de variadas possibilidades de constituição de família e até mesmo da economia conforme os valores tradicionais dos incontáveis grupos sociais é a principal meta do Estado Plurinacional. A lógica passa a ser a inclusão e a luta por direitos historicamente retirados de grupos de identidades diversificadas. Reformas estruturais de cunho institucional encetaram o projeto constitucional na Bolívia e no Equador, e podem facilmente ser passível de adesão por outros Estados latino-americanos.

23 Michel Chossudovsky apresenta os instrumentos utilizados pelas instituições financeiras internacionais para implantação de uma política econômica mundial que mina a soberania econômica dos Estados latinoamericanos, afetando, sobretudo, os mais precários. São ofertados aos Estados endividados um plano de reforma estrutural cujos resultados que os atolam ainda mais e os tornam cada vez mais dependentes de empréstimos internacionais que, segundo o autor, consistem em: “(...) medidas pertinentes à liberalização do comércio, à deseregulamentação do sistema bancário, à privatização de empresas estatais, à reforma fiscal, à privatização de terras cultiváveis, à 'diminuição da pobreza' e ao ‘bom governo'.” (p. 54)

24 Toni Negri, nesse sentido, demonstra que o Estado Plurinacional mudou a situação da Bolívia. Segundo o autor o país se tornou mais forte e dispõe de condições eficientes para se opor à globalização e suas perversidades, senão vejamos: "Em Bolivia, hace tres años, exportábamos 1.600 milliones de dólares, hoy estamos exportando 4.000 milliones de dólares: em dos años hemos casi triplicado la exportación. Eso tiene relación con el potenciamento de sectores productivos, pero también con una mayor capacidad de este gobierno para tomar decisiones. Hasta hace dos años, los gobiernos bolivianos tenían que ir al Fondo Monetario Internacional o al Banco Mundial a pedir dinero para pagar salarios a sus trabajadores. Hoy no tiene por qué pasar por eso: puede pagar salarios con sus proprios recursos.” (p. 49)

Revista da Faculdade Mineira de Direito, v.13, n. 26, jul./dez. 2010 - ISSN 1808-9429. 
Destaca-se como a autodeterminação dos povos se torna pujante com o enaltecimento da diversidade cultural e étnica em países vítimas de um alongado período de massacre. O povo ao recuperar a sua autonomia sobre seu território, sobre a extração de recursos naturais, minerais e hídricos e a determinar as diretrizes do desenvolvimento social, econômico e político, reencontra sua própria soberania.

Isso também se reflete na ordem internacional justamente em função da soberania se desdobrar no aspecto interno e externo. Nesse sentido, o Estado também se desprende da interferência exterior em relação aos seus assuntos particulares pelo fato de suas deliberações serem conduzidas pelo próprio povo. A superação do Estado nacional é a primeira etapa da evolução dessa sociedade embrionária, fruto da constante dinâmica social.

A plurinacionalidade, enquanto um elemento bastante comum no continente latinoamericano, se for utilizada para aproximar os povos de distintos Estados, pode servir-se de ferramenta para conectá-los. A ligação entre culturas e etnias favorece o processo de integração, e o reconhecimento mútuo será um fator capaz de limitar a ocorrência de desavenças entre os diversos grupos sociais, o que conduz à possibilidade de resolução de problemas similares entre países no campo social, econômico e político.

Um Estado com características democráticas e plurais, em que não se prioriza tratamentos às classes diferenciadas, cria condições de reduzir o nível de discriminação. A equalização de direitos suprime a sobreposição de categorias sociais e gera consequiências positivas na luta contra as desigualdades, sobretudo de gênero. Os estilos, crenças, valores, costumes, religiões e outras peculiaridades que compõe o perfil dos povos na América Latina são fatores que integram essa diversidade. Permitir a eliminação desses atributos ou torná-los irrisórios deturpa a história dos primeiros povoadores latino-americanos, fazendo-se com que o futuro se construa sob incertezas e sem direção.

O Estado Plurinacional marca grandes conquistas no presente dos povos originários, porque e os inclui e os reconhece como legítimos detentores do poder político. Para isso foi preciso provocar a ruptura com a intolerância e violência de séculos de dominação. A reforma da constitucional traz em seu bojo uma nova institucionalização baseada no compartilhamento, pelas diversas classes sociais, do poder político e jurídico.

Essas alterações na estrutura Estatal representam uma transição tão vantajosa para os povos latino-americanos, que também criam condições propícias de combate aos efeitos perversos advindos da globalização. A primeira tarefa a se cumprir para impedir a perda do controle do Estado pela ação das empresas transnacionais, pelas instituições financeiras 
internacionais (como Banco Mundial e Fundo Monetário Internacional) e Estados hegemônicos, passa pela remodelagem dos pilares básicos do Estado.

\begin{abstract}
Recently the Plurinational State appeared in Latin America, innovating the constitutionalism of the contemporary world for its daring in promoting the transition from the democratic system of purely representative essence to the participation and dialogue system. This constitutional project abandons the bases of uniform values and religious intolerance, which are typical traits of the national Estate, and it inaugurates a new political order that reverberates in the international sphere. The foundation for the creation of a Estate model, that is based on institution reorganization, is the radical exclusion of social groups (ethnic and cultural), which started during the period of colonization by the Iberian countries and is extended until the present days. The plurinationality directly influences in the construction of a new social, economical and political conjuncture, besides being an excellent factor for the consolidation of the celebrated ideal of Latin America's people integration. The recognition and the preservation of the diversity have certain affinity with the principle of the selfdetermination of people, and are, undoubtedly, a powerful instrument to soften the negative effects of globalization.
\end{abstract}

Keywords: Plurinational State; self-determination of peoples; integration of Latin America; globalization; sovereignty.

\title{
REFERÊNCIAS
}

ALMEIDA, Ileana. EI Estado Plurinacional: valor histórico y liberdad política para los indígenas ecuatorianos. Quito-Ecuador: Ediciones Abya-Yala, 2008.

ALMEIDA, Lúcio Flávio Rodrigues de. Lutas sociais e questões nacionais na América Latina: algumas reflexões. Lutas Sociais $\mathrm{n}^{\circ} 17 / 18-2^{\circ}$ sem. 2006 e $1^{\circ}$ sem. 2007 ISSN 1415854X, p. 64-77. Disponível em: 〈http://www.pucsp.br/neils/downloads/v17_18_lucio.pdf>. Acesso em: 29/10/10.

BROWNLIE, Ian. Princípios de Direito Internacional Público. Lisboa: Fundação Calouste Gulbenkian, 1997.

CHOSSUDOVSKY, Michel. A globalização da pobreza: impactos das reformas do FMI e do Banco Mundial. Tradução: Marylene Pinto Michael. São Paulo: Moderna, 1999.

GRIJALVA, Agustín (2008). EI Estado Plurinacional e Intercultural em la Constitución Ecuatoriana del 2008. Revista Ecuador Debate, n. 75: 49-62. Disponível em: <http://www.ecuadordebate.com/wp-content/uploads/2010/06/Ecuador-debate-75.pdf>. Acesso em: 30/10/10.

KRAUS, Peter A.. Problemas de democratización em los Estados plurinacionales. Revista internacional de filosofia política, ISSN 1132-9432, No 8, 1996, p. 59-80. Disponível em: < http://dialnet.unirioja.es/servlet/articulo?codigo $=2704760 \&$ orden $=186930 \&$ info $=$ link $>$.

Acesso em: 29/10/10. 
MAGAlHÃES, José Luiz Quadros de. O Estado Plurinacional na América Latina. Disponível em: <http://jusvi.com/artigos/38959>. Acesso em: 27/10/10.

MAGALHÃES, José Luiz Quadros de. Plurinacionalidade e cosmopolitismo: a diversidade cultural das cidades e diversidade comportamental nas metrópoles. Disponível em: <http://jus.uol.com.br/revista/texto/14564/plurinacionalidade-ecosmopolitismo-a-diversidade-cultural-das-cidades-e-diversidade-comportamental-nasmetropoles>. Acesso em: 27/10/10.

MÁIZ, Ramon. Nacionalismo y multiculturalismo. Disponível em:

<http://red.pucp.edu.pe/ridei/buscador/files/081116.pdf>. Acesso em: 29/10/10.

NEGRI, Toni [et. al.]. Imperio, multitud y sociedad abigarrada. Buenos Aires: Waldhuter Editores, 2010.

REDIN, Giuliana. Direito à autodeterminação dos povos e desenvolvimento: uma análise a partir das relações internacionais. Passo Fundo: Méritos, IMED, 2006.

SANTOS, Milton. Por uma outra globalização: do pensamento único à consciência universal. 10. ed., Rio de Janeiro: Record, 2003.

SOARES, Mário Lúcio Quintão. Direitos fundamentais e direito comunitário: por uma metódica de direitos fundamentais aplicada às normas comunitárias. Belo Horizonte: Livraria Del Rey Editora, 2000.

TAPIA, Luís 2007 “Una reflexión sobre la idea de Estado plurinacional” en OSAL (Buenos Aires: CLACSO) Año VIII, N² 22, septiembre, p. 47-63. Disponível em: <http://bibliotecavirtual.clacso.org.ar/libros/osal/osal22/D22Tapia.pdf> . Acesso em: 29/10/10.

VITÓRIA, Francisco. Os índios e o direito de guerra: de indis et de jure belli relectiones. Ijuí: Ed. Unijuí, 2006.

WALLERSTEIN, Immanuel. O universalismo europeu: a retórica do poder. Tradução: Beatriz Medina; apresentação Luiz Alberto Moniz Bandeira. São Paulo: Boitempo, 2007. 